\title{
Bupivacaine/ketamine is superior to intra-articu- lar ketamine analgesia following arthroscopic knee surgery
}

\author{
[Un mélange de bupivacaïne et de kétamine est supérieur à la kétamine seule \\ pour l'analgésie intra-articulaire à la suite d'une arthroscopie du genou]
}

Yatindra Kumar Batra MD MNAMs, * Rajesh Mahajan MD, * Sushil Kumar Bangalia MD, * Onkar Nath Nagi MS FAMs, $\uparrow$ Mandeep Singh Dhillon

Purpose: Centroneuraxial and parenteral administration of ketamine has been shown to produce analgesia. However, this analgesia is limited by adverse effects. The purpose of this study was to determine whether ketamine alone or in combination with bupivacaine provides superior pain relief after surgery in patients undergoing knee arthroscopy.

Methods: Sixty patients (classified as ASA status I or II) undergoing arthroscopic meniscus repair during general anesthesia were randomized to receive $1.0 \mathrm{mg} \cdot \mathrm{kg}^{-1}$ ketamine (Group K), $0.25 \%$ bupivacaine (Group B) or a combination of $1.0 \mathrm{mg} \cdot \mathrm{kg}^{-1}$ ketamine and $0.25 \%$ bupivacaine (Group BK) to a total volume of $20 \mathrm{~mL}$ by intra-articular route following surgery. Visual analogue score in the postanesthesia care unit at 0.5, I, 2, 4, 6, 8, 12 and $24 \mathrm{hr}$ after surgery, duration of analgesia and subsequent $24 \mathrm{hr}$ consumption of rescue analgesic (dextroproxyphene/ acetaminophen) were evaluated.

Results: The results showed significantly higher pain scores in Group K as compared to Group B and Group BK. The duration of analgesia was significantly shorter in Group $\mathrm{K}$ as compared to the other two groups (Group B $=5.7 \pm 0.8$; Group BK $=5$.I \pm I.I vs Group K = I.7 $\pm 0.9 \mathrm{hr} ; P<0.05)$. However, $24 \mathrm{hr}$ consumption of analgesic was similar in the three groups.

Conclusion: We conclude that intra-articular bupivacaine-ketamine combination provides better pain relief than intra-articular ketamine after day care arthroscopic knee surgery.
Objectif: L'administration centro-neuraxiale et parentérale de kétamine peut produire une analgésie, limitée toutefois par des effets indésirables. Nous avons voulu vérifier la qualité de l'analgésie selon l'utilisation de kétamine seule ou en combinaison avec de la bupivacaïne à la suite d'une arthroscopie du genou.

Méthode : Soixante patients, d'état physique ASA I ou II, devant subir la réparation arthroscopique d'un ménisque sous anesthésie générale, ont été répartis au hasard pour recevoir $1,0 \mathrm{mg} \cdot \mathrm{kg}^{-1} \mathrm{de}$ kétamine (Groupe K), de la bupivacaïne à 0,25\% (Groupe B) ou une combinaison de $1,0 \mathrm{mg} \cdot \mathrm{kg}^{-1}$ de kétamine et de bupivacaïne à 0,25\% (Groupe BK) dans un volume total de $20 \mathrm{~mL}$ administré par voie intra-articulaire après l'opération. Les scores de l'échelle visuelle analogique $0,5, I, 2,4,6,8,12$ et 24 h après l'opération, la durée de l'analgésie et les analgésiques supplémentaires pendant $24 \mathrm{~h}$ de plus (dextroproxyphène/acétaminophène) ont été enregistrés.

Résultats : Les scores de douleur ont été significativement plus élevés chez les patients du Groupe $K$, comparé aux Groupes $B$ et $B K$. La durée de l'analgésie a été plus courte aussi dans le Groupe K (Groupe $B=5,7 \pm 0,8$; Groupe $B K=5, I \pm I$ I I vs Groupe $K$ $=I, 7 \pm 0,9 \mathrm{~h} ; P<0,05)$. La consommation d'analgésique supplémentaire a toutefois été similaire dans les trois groupes.

Conclusion : L'administration intra-articulaire d'une combinaison de bupivacaïne et de kétamine fournit une meilleure analgésie que la kétamine seule après une arthroscopie du genou en chirurgie d'un jour.

From the Department of Anesthesia and Intensive Care* and the Department of Orthopedic Surgery, $†$ Postgraduate Institute of Medical Education and Research (PGIMER), Chandigarh, India.

Address correspondence to: Dr. Y.K. Batra, Department of Anesthesia and Intensive Care, Post-graduate Institute of Medical Education

\& Research, Chandigarh-160012, India. Phone: +91-172-2715545; Fax: +91-172-2744401; E-mail: ykbatra@glide.net.in Accepted for publication January 31, 2005.

Revision accepted April 25, 2005. 
A

RTHROSCOPIC knee surgery is commonly performed as an outpatient procedure. Intra-articular (IA) local anesthetics are often used for prevention of pain after arthroscopic knee surgery. ${ }^{1,2}$ However the mean duration of analgesia provided by local anesthetics is short, and patients may need supplementary analgesia, possibly delaying their discharge. To overcome this, various drugs including opioids, non-steroidal anti-inflammatory drugs (NSAIDs) and neostigmine have been used for IA injection with local anesthetics, and effects have been variable. ${ }^{3-6}$ The search continues for an ideal analgesic technique which is site-specific, long lasting, easily administered and has a high therapeutic index.

Ketamine has been found to interact with a number of receptors like opioids, muscaranic and N-methylD-aspartate receptors (NMDAr). ${ }^{7}$ Although central NMDAr, especially when located in the spinal cord have received a great deal of attention, recent evidence suggests that NMDAr located in peripheral somatic and visceral pain pathways play an important role in nociception. ${ }^{8}$ NMDAr have been found to exist in joints, as demonstrated in the rat model by $\mathrm{Yu}$ et al. ${ }^{9}$ Ketamine had been reported to have peripheral analgesic effects with variable duration on measurement of pain and hyperalgesia. Recently, Huang et al. have shown that $0.5 \mathrm{mg} \cdot \mathrm{kg}^{-1}$ of IA ketamine does not produce postoperative analgesia after knee arthroplasty. ${ }^{10}$ However, its efficacy in a higher dose when combined with a local anesthetic, is still not studied. Thus, we performed a double-blind, randomized study in patients undergoing knee arthroscopy to evaluate postoperative analgesia by IA ketamine when administered alone, or in combination with bupivacaine.

\section{Materials and methods}

After obtaining local Ethics Committee approval and written informed consent, 60 unpremedicated ASA, physical status I and II patients scheduled for outpatient arthroscopic knee surgery were enrolled in the study. Patients < 18 yr of age, those with relevant drug allergy, use of oral narcotics preoperatively or concurrent use of NSAIDS/opioid therapy and those requiring knee drainage were excluded from the study. Before the operation all patients received instructions for using a 100-mm visual analogue scale (VAS) score with $0=$ no pain, to $100=$ the worst imaginable pain, and baseline pain scores were recorded. Pain was assessed by a single interviewer who was not aware of the study medication.

Patients received general anesthesia, in adherence with the study protocol. No premedication was given. After placement of a routine monitor, anesthesia was induced with $2 \mu \mathrm{g} \cdot \mathrm{kg}^{-1}$ iv fentanyl, $2 \mathrm{mg} \cdot \mathrm{kg}^{-1}$ iv propofol, and maintained with $66 \% \mathrm{~N}_{2} \mathrm{O}$ in $\mathrm{O}_{2}$ and 1 to $2 \%$ inspired isoflurane. Patients breathed spontaneously via laryngeal mask airway for the duration of the procedure. No other supplementary analgesic medication was given during the operation after the first dose of fentanyl. Before surgical incision, a pneumatic tourniquet at a pressure of $300 \mathrm{mmHg}$ was applied to all patients. The surgeon performed all surgical procedures using a standard surgical technique. At the end of the operation, patients were allocated using a randomized number table, into one of three groups, consisting of 20 patients each. Group $\mathrm{K}$ received 1 $\mathrm{mg} \cdot \mathrm{kg}^{-1}$ ketamine (Aneket 5\%, Neon Laboratories, Mumbai, India), Group B received $0.25 \%$ bupivacaine and Group BK received $0.25 \%$ bupivacaine with ketamine $1 \mathrm{mg} \cdot \mathrm{kg}^{-1}$. The volume of injectate was standardized at $20 \mathrm{~mL}$. The study solution, supplied in a coded syringe, was injected into the knee joint through an arthroscope at the end of surgery, ten minutes before the tourniquet release. After termination of anesthesia, patients were returned to the recovery room, and were discharged home according to normal clinical criteria.

Arrival at the postanesthesia care unit was recorded as time zero. The VAS was assessed at predetermined intervals following surgery $(0.5,1,2,4,6,8,12$ and $24 \mathrm{hr}$ ) after the patients were instructed to bend the operated knee to a $90^{\circ}$ angle. Analgesic rescue medication consisted of oral Wygesic $\AA$ tablets (dextroproxyphene $65 \mathrm{mg}$ and acetaminophen $650 \mathrm{mg}$ ) as required. Duration of effective analgesia was measured from time of completion of surgery until first requirement of rescue analgesia. When patients were discharged from the hospital, they were given a data sheet and were asked to rate their pain intensity on the VAS at the predetermined times, and record their analgesic consumption. All patients were contacted by the anesthesiologist the day following surgery for an interview, to evaluate postoperative pain and adverse effects such as hallucinations, nausea and vomiting. The patientrecorded data were subsequently collected.

Analysis of variance (ANOVA) was used to compare pain scores in three different groups and the least significant difference method used for pairwise comparisons of mean at each time. The time to first analgesic dose and the $24 \mathrm{hr}$ analgesic requirement were analyzed using a one way ANOVA. Post-hoc comparisons were made using the Newman-Keuls test. The Chi-square analysis of contingency table was used for comparison of categorized data. Data are presented as mean \pm SD. A $P$ value of $<0.05$ was considered significant. Based upon a SD of $20 \mathrm{~mm}$ (estimated from 
TABLE I Patient data and preoperative VAS Scores (all values mean $\pm S D$ )

\begin{tabular}{llll}
\hline & Group $K$ & Group B & Group BK \\
\hline Sex: M/F & $14: 6$ & $16: 4$ & $14: 8$ \\
Age (yr) & $38 \pm 4.3$ & $44 \pm 3$ & $35 \pm 4$ \\
Weight (kg) & $74 \pm 2$ & $68 \pm 3$ & $72 \pm 4$ \\
Tourniquet time (min) & $42 \pm 2$ & $40 \pm 4$ & $47 \pm 3$ \\
Preoperative VAS (mm) & $19 \pm 5$ & $18 \pm 6$ & $17 \pm 4$ \\
\hline
\end{tabular}

VAS $=$ visual analogue scale. $P>0.05$.

TABLE II Postoperative analgesic consumption

\begin{tabular}{lllll}
\hline & Group K & Group B & Group BK & P-palue \\
\hline $\begin{array}{l}\text { Time to first analgesic } \\
\text { consumption (hr) }\end{array}$ & $1.7 \pm 0.9^{*} 5.7 \pm 0.8$ & $5.1 \pm 1.1$ & $<0.05$ \\
$\begin{array}{l}\text { Number of tablets } \\
\text { (Wygesic }\left({ }^{\text {) }} \text { ) consumed/day }\right.\end{array}$ & $4.1 \pm 0.8$ & $3.9 \pm 0.9$ & $3.5 \pm 1.0$ & $P=0.07$ \\
$\begin{array}{l}\text { *Group K significantly less than Groups B and BK. Group BK did } \\
\text { not differ from Group B. }\end{array}$
\end{tabular}

previous VAS after knee arthroscopy in patients given IA analgesia), a group size of 20 patients would be sufficient to detect a difference of $20 \mathrm{~mm}$ of the VAS at $0.5 \mathrm{hr}$ postoperatively.

\section{Results}

All patients completed the study protocol. Patient characteristics are presented in Table I. There were no differences between groups with regards to age, weight, height, ASA status, gender and preoperative VAS scores. There were no differences with respect to pain scores from one to four hours postoperatively between Groups B and BK $(P>0.05)$, but scores were significantly higher in Group $\mathrm{K}(P<0.05)$, (Figure). Thereafter VAS scores were similar during the remainder of the study period amongst the three groups. Patients receiving IA ketamine alone requested rescue analgesic earlier than patients in the other two groups $(P<0.01)$. However, the mean cumulative $24 \mathrm{hr}$ analgesic consumption was not different amongst the three groups $(P>0.05)$, (Table II). Complications included hemoarthrosis in one patient in each of Groups B and BK that resolved with conservative treatment. No central side effects attributable to any of the test drugs were observed.

\section{Discussion}

Ketamine has been found to be effective by neuraxial, oral and parenteral routes. Clinically, it has been reported to produce not only general, but also local

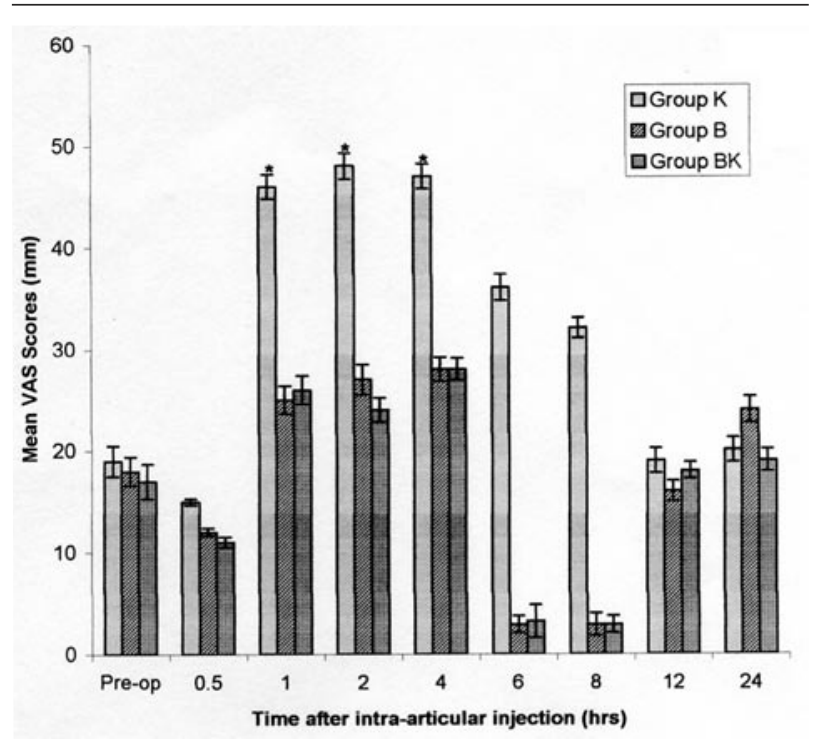

FIGURE Mean visual analogue scale (VAS) scores following intra-articular injection in all three groups. ${ }^{*} p<0.05$.

anesthesia. ${ }^{7}$ It interacts with a multitude of receptors including opioid, cholinergic, adrenergic, serotonergic and NMDAr, all of which have a significant role in analgesia. ${ }^{7,8}$ Immunohistochemical studies have confirmed NMDAr in primary afferent neurons, neuromuscular junctions, tendons and other peripheral tissue. In a rat model of temporomandibular joint (TMJ) inflammation induced with mustard oil, Yu et al. demonstrated the involvement of NMDAr mechanism in jaw electromyographic activity and plasma extravasation induced by inflammatory irritant application of TMJ. ${ }^{9}$ The magnitude of both masseter and diagastric electromyographic responses was proportional to nociceptive trigeminal brainstem neuronal activity. These were significantly reduced by the NMDA antagonist MK-801 administered into TMJ, but had no effect on plasma extravasation, which is characteristic of acute inflammation.

IA administration of ketamine was found to attenuate the nociceptive behaviour produced by injection of a mixture of kaoloin and carrageenan into the joint as long as two hours after the treatment in rats. ${ }^{11}$ Tverskoy et al., showed that the addition of ketamine to bupivacaine for wound infiltration could prolong the analgesic duration and increase the pain threshold of post-herniorraphy pain. ${ }^{12}$ However, we could not demonstrate any significant analgesic benefit con- 
ferred by IA ketamine given alone or in combination with bupivacaine, as measured by VAS scores or analgesic consumption. As previous studies have shown that IA bupivacaine was more effective than saline, we chose not to use a placebo group. ${ }^{13}$ The bupivacaine only group was, in effect, the control group because we were investigating specifically the effect of adding ketamine to bupivacaine.

Excitatory amino acids like glutamate and aspartate act on NMDAr. ${ }^{14,15}$ Following induction of acute joint inflammation, there are both central and peripheral neuronal changes. Peripherally, there is sensitization and increase in glutamate content in articular afferent fibres. Centrally, sensitization of dorsal horn neurons occurs leading to increased responses to peripheral mechanical and chemical stimuli. Coincident with these neural changes is an increased release of glutamate and aspartate in the dorsal horn of spinal cord. This release occurs in two phases: an increase at the time of injection and a late prolonged phase (3.5-8 hr). ${ }^{15}$ Sluka et al. have shown that although increased late phase release of glutamate was reversed by posttreatment of spinal cord with NMDA antagonist AP7, late phase release of aspartate in arthritis animals is unaffected by post-treatment of spinal cord with AP7. This continued increase in release of aspartate appears to be independent of NMDAr activation following initiation of events activated by induction of arthritis. ${ }^{15}$ This selective action of NMDA antagonists on nociception and inflammation, as evident by an inability to prevent plasma extravasation (approximating to inflammation) of arthritic joint ${ }^{9}$ and an inability to prevent continued release of aspartate at the central level ${ }^{14,15}$ may be responsible for lack of significant analgesic effect with IA ketamine. In a recent study Zhang and his associates examined whether IA pretreatment with ketamine and memantine suppressed arthritic pain-related behaviour and spinal c-Fos expression induced by carrageenan injection into the knee joint in rats. The results suggest that IA ketamine $(1 \mathrm{mg})$ significantly prevented pain-related behaviour and also suppressed spinal c-Fos expression in the lamina I-II and lamina V-VI at the L3-L4 spinal level. ${ }^{16}$ Based on this study, we selected a similar dose of IA ketamine alone or in combination with bupivacaine to determine its efficacy for postoperative pain relief following day care arthroscopy. Our results corroborate with that of Huang et al. who examined the peripheral analgesic effect of ketamine administration via the IA route postoperatively. They showed no differences in VAS pain scores at rest and during motion amongst three groups of patients receiving $0.5 \mathrm{mg} \cdot \mathrm{kg}^{-1}$ body weight diluted with saline, $0.5 \mathrm{mg} \cdot \mathrm{kg}^{-1}$ of $i m$ ketamine and IA saline (control) during a 24-hr observation period. ${ }^{10}$ Our patients were asked to flex their operative knee to $90^{\circ}$ before scoring their pain. By stressing the joint, the degree of pain and adequacy of analgesia are better assessed. Such testing has been recommended for the assessment of postoperative pain, ${ }^{5}$ especially when assessing outpatients for discharge home. ${ }^{17}$

After IA administration, serum concentration of local anesthetics like bupivacaine and lidocaine has been found to be well below the concentration associated with toxic reaction and within the range considered to be safe. ${ }^{18,19}$ The absorption of bupivacaine from the knee joint is significantly lower from the epidural space. ${ }^{20}$ Poor absorption of the drug from the IA space due to poor vascularity may have resulted in serum concentration of ketamine too low to have central analgesic effect, in contrast to the central effects seen with centroneuraxial use of ketamine. ${ }^{21}$ The number of NMDAr on peripheral nerve fibres increases akin to induction of new synthesis and migration of opioid receptor from dorsal root ganglion to the peripheral nerve ending during inflammation. In addition, the breakdown of the perineurium by inflammation increases the accessibility of peripheral opioid receptors. ${ }^{7,22,23}$ Although this has been proposed as a mechanism of analgesic efficacy of IA morphine, ${ }^{10,24}$ increase in receptors does not necessarily equate with effective analgesia with IA morphine. ${ }^{25,26}$ Such discrepancy between analgesic effects and receptor population may also exist for ketamine.

The affinity of opioid receptors by ketamine is 10,000 fold weaker than that of morphine. ${ }^{7}$ Picard et al. also found that the analgesic effect of ketamine via peripheral opioids receptor is weak, if any. ${ }^{27}$ In vitro studies have shown that depression of sodium channel conduction in neural tissues occurs only at concentrations far in excess of those used clinically. ${ }^{28}$ Further, Durrani et al. in their study of $i v$ regional anesthesia found that doses of ketamine higher than used in our study were ineffective in producing local anesthetic action. ${ }^{29}$ Hence, local anesthetic action of ketamine may be insufficient to provide sufficient intensity and duration of analgesia. In conclusion, ketamine $1.0 \mathrm{mg} \cdot \mathrm{kg}^{-1}$ alone or in combination with IA bupivacaine $0.25 \%$ does not improve analgesia provided with bupivacaine alone. Further studies are required to examine the peripheral mechanism of ketamine on NMDA receptors.

\section{References}

1 Kaeding CC, Hill JA, Katz J, Benson L. Bupivacaine use after knee arthroscopy: pharmacokinetics and pain control study. Arthroscopy 1990; 6: 33-9.

2 Chirwa SS, MacLeod BA, Day B. Intraarticular 
bupivacaine (Marcaine) after arthroscopic meniscectomy: a randomized double-blind controlled study. Arthrosocopy 1989; 5: 33-5.

3 Reuben SS, Connelly NR. Postoperative analgesia for outpatient arthroscopic knee surgery with intraarticular bupivacaine and ketorolac. Anesth Analg 1995; 80: 1154-7.

4 Gentili M, Houssel P, Osman M, Henel D, Juhel A, Bonnet F. Intra-articular morphine and clonidine produce comparable analgesia but the combination is not more effective. Br J Anaesth 1997; 79: 660-1.

5 rang LC, Chen LM, Wang CJ, Buerkle $H$. Postoperative analgesia by intraarticular neostigmine in patients undergoing knee arthroscopy. Anesthesiology 1998; 88: 334-9.

6 Stein C, Comisel K, Haimerl E, et al. Analgesic effect of intraarticular morphine after arthroscopic knee surgery. N Engl J Med 1991; 325: 1123-6.

7 Hirota K, Lambert DG. Ketamine: its mechanism(s) of action and unusual clinical uses (Editorial). Br J Anaesth 1996; 77: 441-4.

8 Petrenko AB, Yamakura T, Baba H, Shimoji K. The role of N-methyl-D-aspartate (NMDA) receptors in pain: a review. Anesth Analg 2003; 97: 1108-16.

9 Үu XM, Sessle BJ, Haas DA, Izzo A, Vernon $H, H u$ $J W$. Involvement of NMDA receptor mechanisms in jaw electromyographic activity and plasma extravasation induced by inflammatory irritant application to temporomandibular joint region of rats. Pain 1996; 68 169-78.

10 Huang GS, Yeh CC, Kong SS, Lin TC, Ho ST, Wong CS. Intra-aticular ketamine for pain control following arthroscopic knee surgery. Acta Anaesthesiol Sin 2000; 38: 131-6.

11 Lawand NB, Wilis WD, Westlaund KN. Excitatory amino acid receptor involvement in peripheral nociceptive transmission in rats. Eur J Pharmacol 1997; 324: 169-77.

12 Tverskoy M, Oren M, Vaskovich M, Dashkovsky I, Kissin L. Ketamine enhances local anesthetic and analgesic effects of bupivacaine by peripheral mechanism: a study of postoperative patients. Neurosci Lett 1996; 215: 5-8.

13 Laurent SC, Nolan JP, Pozo JL, Jones CJ. Addition of morphine to intra-articular bupivacaine does not improve analgesia after day-case arthroscopy. Br J Anaesth 1994; $72:$ 170-3.

14 Sluka KA, Westlund KN. Spinal cord amino acid release and content in an arthritis model: the effects of pretreatment with non-NMDA, NMDA and NKI receptor antagonists. Brain Res 1993; 627: 89-103.

15 Sluka KA, Jordan HH, Willis WD, Westlund KN. Differential effects of N-methyl-D-asparatate (NMDA) and non-NMDA receptor antagonists on spinal release of amino acids after development of acute arthritis in rats. Brain Res 1994; 664: 77-84.

16 Zhang GH, Min SS, Lee KS, et al. Intraarticular pretreatment with ketamine and memantine could prevent arthritic pain: relevance to the decrease of spinal c-Fos expression in rats. Anesth Analg 2004; 99: 152-8.

17 Loper KA, Ready LB, Downey M, et al. Epidural and intravenous fentanyl infusions are clinically equivalent after knee surgery. Anesth Analg 1990; 70: 72-5.

18 Katz JA, Kaeding CS, Hill JR, Henthorn TK. The pharmacokinetics of bupivacaine when injected intraarticularly after knee arthroscopy. Anesth Analg 1988; 67: 872-5.

19 Weiker GG, Kuivila TE, Pippinger CE. Serum lidocaine and bupivacaine levels in local technique knee arthroscopy. Am J Sports Med 1991; 19: 499-502.

20 Yanli $\Upsilon$, Eren $A$. The effect of extradural ketamine on onset time and sensory block in extradural anesthesia with bupivacaine. Anaesthesia 1996; 51: 84-6.

21 Hawksworth C, Serpell M. Intrathecal anesthesia with ketamine. Reg Anesth Pain Med 1998; 23: 283-8.

22 Hassan AH, Ableitner A, Stein C, Herz A. Inflammation of the rat paw enchances axonal transport of opioid receptors in the sciatic nerve and increases their density in the inflamed tissue. Neuroscience 1993; 55: 185-95.

23 Antonijevic I, Mousa SA, Schafer M, Stein C. Perineurial defect and peripheral opioid analgesia in inflammation. J Neurosci 1995; 15(1Ptl): 165-72.

24 Rosseland LA, Stubhang A, Grevbo F, Reikeras $O$, Breivik $H$. Effective pain relief from intra-articular saline with or without morphine $2 \mathrm{mg}$ in patients with moderate-to-severe pain after knee arthroscopy: a randomized, double-blind controlled clinical study. Acta Anaesthesiol Scand 2003; 47: 732-8.

25 Raja SN, Dickstein RE, Johnson CA. Comparison of postoperative analgesic effects of intraarticular bupivacaine and morphine following arthroscopic knee surgery. Anesthesiology 1992; 77: 1143-7.

26 Heard SO, Edwards WT, Ferrari D, et al. Analgesic effect of intraarticular bupivacaine or morphine after arthroscopic knee surgery: a randomized, prospective, double-blind study. Anesth Analg 1992; 74: 822-6.

27 Picard PR, Tramer MR, McQuay HJ, Moore RA. Analgesic efficacy of peripheral opioids (all except intra-articular): a qualitative systematic review of randomised controlled trials. Pain 1997; 72: 309-18.

28 Frenkel $C$, Urban $B W$. Molecular actions of racemic ketamine on human CNS sodium channels. Br J Anaesth 1992; 69: 292-7.

29 Durrani Z, Winnie AP, Zsigmond EK, Burnett ML. Ketamine for intravenous regional anesthesia. Anesth Analg 1989; 68: 328-32. 